\title{
The study of the impact of genetically modified soybean imports on China's food safety management
}

\author{
YinTong $\mathrm{Yu}^{*}$ \\ College of Science \& Technology, Ningbo University, Ningbo, Zhejiang 315300, China
}

Received: 4 February 2021 / Accepted: 9 June 2021

\begin{abstract}
With the widespread application of genetically modified technology, the proportion of genetically modified crops in the food sector has gradually increased. Of all of China's imported crops, genetically modified soybeans account for more than $75 \%$. However, the safety issue associated with daily consumption, the contamination issue related to planting, as well as the attendant scientific and ethical issues have posed new challenges to the regulatory system of food safety of China. By examining the judicial and administrative management cases concerned, this author finds that the power to exercise effective safety control in regard to Genetically Modified Organism (GMO) rests with the low tier of government under the current system. In addition, the managerial measures are not well defined and targeted. The rules and regulations of China apparently fall short of the standards required of by international treaties. As a result, it is imperative for the higher tier of government to be empowered to handle the management of GMO and fine-tune the management and make some useful improvements. It is also necessary for Chinese authorities to devise a targeted system and make Chinese rules and regulations move closer to international treaties.
\end{abstract}

Keywords: Genetically modified (GM) soybean imports / the food safety act / the foreign trade act / regulations on the safety control of GMO in agriculture

\section{Introduction}

Genetically Modified (GM) technology refers to biotechnology technology that transfer organism's to another organism. Since the beginning of trials of genetically modified planting technology in the United States in the 1970s, genetically modified agriculture has been developing for nearly 50 years. In the mid-1990s, the GM planting started the process of commercialization. After that, GM planting has been seeing a rapid development. A report titled Global Status of Commercialized Biotech/GM Crops: 2018 released by The International Service for the Acquisition of Agri-biotech Applications (ISAAA) ${ }^{1}$ pointed out that by the end of 2018 , the world had planted 190 million hectares of biotech crops, 113 times as many as the hectares of 1996. A total of 26 countries and regions planted biotech crops and another 44 countries and regions

\footnotetext{
* Corresponding author: ytcnow0@163.com

${ }^{1}$ A small, nonprofit international organization aimed at promoting the application of biotechnology, the major providers of operation costs include the Department of Agriculture, the Grain Council of America, the German Industrial Corporation and Monsanto of the US, etc.
}

imported biotech crops [1]. As far as China is concerned, genetically modified crops have been increasingly becoming an important part of its people's food intake. Taking soybean oil as an example, we find that in 2019, China consumed a total of 16.67 million tons of soybean oil and much of which relied on GM soybeans for raw material, according to the departments handling commercial affairs [2]. To China, the safety of GM crops is not only a matter of agricultural safety, but also a matter of food safety. This paper is aims to find out the problems of GM soybean imports on China's food safety management, and try to give suggestion for improvement.

As a matter of fact, the rapid development of GM planting has never been free of controversies, particularly in the fields of safety and supervision. The first doubt concerning the safety issue of GM crops was raised by Losey et al., professor of Cornell University. In his research paper titled "Transgenic Pollen Harms Monarch Larvae" published by Nature in 1999, he pointed out that larvae of the monarch butterfly, Danaus plexippus, reared on milkweed leaves dusted with pollen from Bacillus thuringiensis $(B t)$ corn, grew more slowly and suffered a mortality as high as $44 \%$ than larvae reared on leaves dusted with untransformed corn pollen or on leaves without pollen [3]. The study on the potential threats of 
Table 1. The situation of pregnant goats fed with GM soybeans and fed with non-GM soybeans.

\begin{tabular}{lcc}
\hline & Pregnant goats fed with GM soybeans & Pregnant goats fed with non-GM soybeans \\
\hline BW $(\mathrm{kg})$ & 10.73 & 11.68 \\
Spleen $(\mathrm{g})$ & 30.83 & 36.03 \\
Liver $(\mathrm{g})$ & 243.3 & 312.2 \\
Kidney $(\mathrm{g})$ & 59.11 & 77.46 \\
Heart $(\mathrm{g})$ & 69.61 & 106.4 \\
\hline
\end{tabular}

GM crops in the field of biology also captured the attention of scholars in other fields, particularly the scholars in the field of law. On Jan 29, 2000, the contracting countries of The Convention on Biodiversity passed The Cartagena Protocol on Biodiversity, establishing the "precautionary principle" based on Item 15 of The Rio Declaration and aiming to help member countries to achieve the safe handling, transport and use of living modified organisms (LMOs) resulting from modern biotech that may have adverse effects on biodiversity and human health [4]. Thereafter, the issue of regulation of GM crops based on this principle was starting to get noticed. Schnier, professor of Law School of Georgetown University elaborated on the advantages and disadvantages of GM crops in Genetically Modified Organisms and the Cartagena Protocol. He also conducted insightful analysis of the precautionary system established by The Cartagena Protocol on Biodiversity. According to Schnier, although The Cartagena Protocol on Biodiversity may not be applied to all bio safety events, it was effective in information sharing and import regulation under the precautionary system of the protocol as well. He believed that this protocol may indeed play an active role in tackling the controversies related to GM crops should the protocol can be strictly enforced [5]. Since then, precautionary principle has formed the main theoretical basis for regulating research into GM crops. Later, the application of this principle in judicial practice concerning GM crops was taken into research category. Lamping and Matthias conducted in-depth analysis of the verdicts concerning GM crops given by the European Court of Justice in Shackles for Bees? The ECJ's Judgment on GMO-Contaminated Honey [6].

\section{Controversial issues surrounding GM crops}

GM crops have constantly been plagued with various controversies since the advent of this technology. The controversies surrounding food safety center on the following aspects.

\subsection{The safety issue of food intake}

Although there is no direct evidence to prove that consuming GM crops that have been approved for commercial use can cause harm to human body, GM foods may indeed have potential safety risks. Apart from American scholars, Jonathan Latham from Italy published his study in 2015, claiming that compared with goats fed with non-genetically-engineered soybeans, the pregnant goats fed with genetically engineered soybeans had offspring growing more slowly and consequently were smaller in size [7]. This finding was further supported by studies of other Italian scholars. For example, the experiment study of Tudisco and some others in the University of Naples found that the weight of internal organs of the offspring of goats fed with oat hay containing GM elements slaughtered at $60 \pm 7$ days of age was evidently lighter than those of the offspring of goats fed with oat hay without any GM elements [8]. Table 1 presents the detailed data.

Although the data have not received widespread attention from academia worldwide and the validity of method used for this study is yet to be tested, the findings of this study do show that consumption of GM soybeans by humans might have some risks.

\subsection{The safety issue of planting}

The impact on the original crop planting environment is another controversial issue caused by GM technology. Opponents of GM plants believe that GM crops have the potential to alter the original planting environments, making the soil hard to accommodate to different types of crops. This point is supported by the findings of some studies. For example, a research paper titled "The Effect of Glyphosate-Resistant Transgenic Soybean (RRS) on the Number and Diversity of Rhizosphere Soil Bacteria" co-authored by Xu Guanghui, Wang Hongan and Liu Jia pointed out that RRS may reduce the number of rhizosphere soil bacteria and the diversity of bacterial communities to varying degrees [9].

$$
\begin{aligned}
\operatorname{Dsh}=\sum \operatorname{PilnPi} & =\sum(\mathrm{Ni} / \mathrm{N}) \ln (\mathrm{Ni} / \mathrm{N}), \\
\mathrm{Jsh} & =\mathrm{Dsh} / \mathrm{InS}
\end{aligned}
$$

This formula provides a quantitative description of the diversity $\left(D_{\mathrm{sh}}\right)$ and uniformity $\left(J_{\mathrm{sh}}\right)$ of the bacterial community in the rhizosphere soil based on the ratio of the peak area of the band to the total area of all peaks. By cluster analyzing the experimental data, the authors found that the diversity and uniformity of the bacterial community in the rhizosphere soil of the glyphosateresistant genetically modified soybean (RRS) is significantly lower than that of the parental non-transgenic 
Table 2. The situation of soil with GM corps and Non-GM corps with GM soybeans and fed with non-GM soybeans.

\begin{tabular}{lll}
\hline & $\begin{array}{l}\text { Diversity of bacteria community } \\
\text { in rhizosphere soil }\left(D_{\text {sh }}\right)\end{array}$ & $\begin{array}{l}\text { Evenness of bacteria community } \\
\text { in rhizosphere soil }\left(J_{\text {sh }}\right)\end{array}$ \\
\hline Glyphosate-resistant GM soybean(RRS) & $3.59 \pm 0.01 \mathrm{~b}$ & $0.93 \pm 0.01 \mathrm{a}$ \\
Parental non-transgenic soybean (RRSS) & $3.81 \pm 0.02 \mathrm{a}$ & $0.97 \pm 0.02 \mathrm{a}$ \\
Dongnong 42 (D-42) & $3.73 \pm 0.02 \mathrm{ab}$ & $0.96 \pm 0.02 \mathrm{a}$ \\
Dongnong 46 (D-46) & $3.63 \pm 0.06 \mathrm{~b}$ & $0.94 \pm 0.01 \mathrm{a}$ \\
Glycine soja (Y-S) & $3.75 \pm 0.07 \mathrm{ab}$ & $0.95 \pm 0.01 \mathrm{a}$ \\
\hline
\end{tabular}

Table 3. Specific radioactivity of Bt gene in soil accounted for amount of initial introduction (\%).

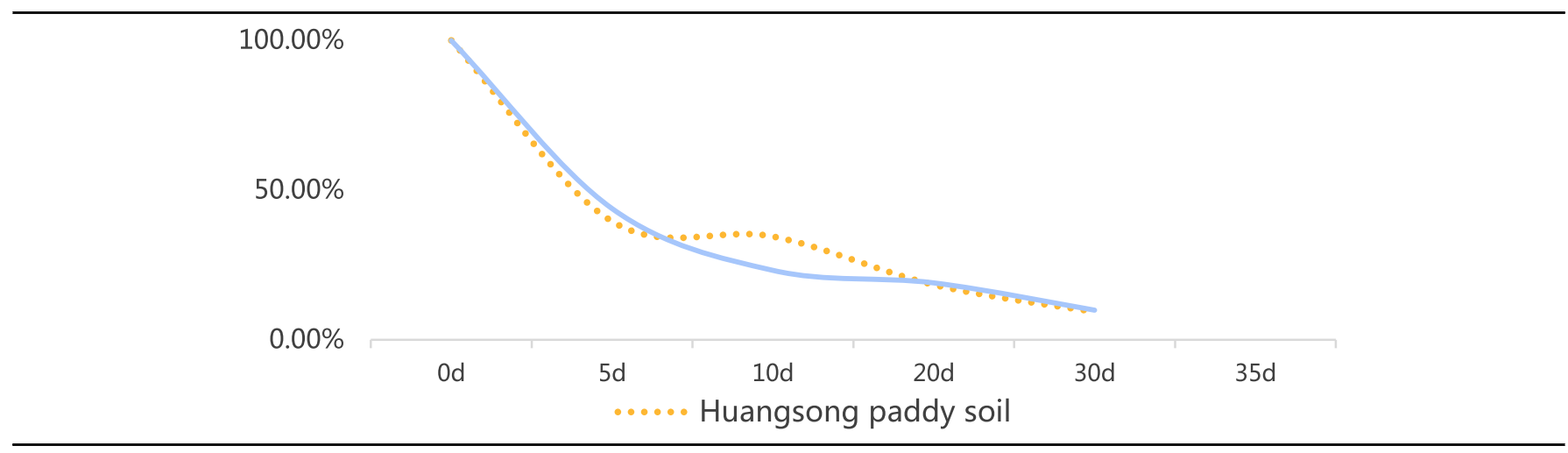

soybean (RRSS) and Dongnong 42 (D-42), Dongnong 46 (D-46) and Glycine soja (YS). The data are presented in Table 2.

It should be noted that although research shows that glyphosate-resistant GM soybean (RRS) may be conducive to the growth of fungi in rhizosphere soil [10]. However, the impact of GM crops on the original planting environment is also a factor needed to be considered should GM foods be imported.

\subsection{The genetic contamination issue}

The so-called genetic contamination refers to the uncontrolled transfer of genes of GM crops and as a result the genes of GM crops spread to other non-GM crops. The earliest report of such case happened in the early 21st century when a farm producing non-GM crops in Texas of America detected the genes of GM corns grown in nearby fields. It was later confirmed that it was caused by the cross-pollination of bees between the two areas [11]. Furthermore, some research institutions have found that the insect-resistant rice straw containing the Bacillus Thuringiensis gene (also referred to as BT gene) can maintain the exogenous protein, which is the BT gene, for a long time after straw incorporation. Through the observation of the specific radioactivity of the BT gene in the insect-resistant rice accounted for the amount of initial introduction, it can be found that the BT gene in the insect-resistant rice can at least be kept in several common types of soils after the straw is returned to the field for more than one month. The Table 3 presents the detailed data [12].

According to the authoritative media, there is no evidence shows that genetic contamination will affect the human body directly [13]. However, it remains to be uncertain whether or not the mechanism of genetic contamination is due to cross-pollination or some other reproduction activities.

\subsection{Ethical issue}

In the process of configuring GM crops, scientists can not only embed various types of plant genes in the crops, they can also embed animal or even human genes in the crops. While these operations could provide scientists with many new ways of thinking, they provoke bitter controversies, particularly in the field of ethics. According to media reports, a Canadian bio-pharmaceutical company added human genes to plants through GM technology and produced a safflower that could generate insulin [14]. This type of study had the potential to blur the boundaries between humans and non-humans. According to scientists, if it is acceptable to produce medicines by altering plant traits through human genes, then there will be no ethical obstacles to clone humans. If we make human genes as the sole criterion to distinguish human and non- 
human, then consuming crops containing human genes is no different than cannibalism. Although ethical issues do not belong to the category of food safety in the general sense, ethical issues are still the important factors to be considered when the safety issue is under evaluation given that food safety is irretrievably linked to nationality, religion as well as social traditions.

\section{Cases concerning the safety of GM foods}

As a matter of fact, the problems associated with the regulatory system for the safety of GM soybeans does not necessarily exist in artificial environments or in other countries. In recent years, cases related to the safety of GM foods have indeed happened now and then.

In fact, the problem of the regulatory system for the safety of genetically modified soybean food does not only exist in the experimental environment or in other countries. In recent years, domestic cases related to the safety of genetically modified foods have also occurred from time to time.

\subsection{The case of Yuqan v. Lotte Mart of Jiangsu, China National Foodstuffs Marketing Co, Ltd, China Oil \& Foodstuff Co, Ltd Donghai Branch}

In May 2015, Wang Quan, a lawyer of Huai'an of Jiangsu Province filed a lawsuit against Lott Mart of Jiangsu, China National Foodstuffs Marketing Co, Ltd, and China Oil \& Foodstuff Co, Ltd Donghai Branch for producing and selling GM oil with fonts of label much smaller than the requirements set by national standards, thus violating Regulations on the Safety Management of Agricultural GMOs [15] and The Measures for the Administration of Labeling of GMOs [16] and demanding compensation for economic losses. Wang Quan further requested the court to rule that the label of the GM foods involved in this case should be redesigned before they could be marketed. However, the court of second instance rejected Wang Quan's plea, arguing that the labeling of GM foods in this case met the standard of the industry [17].

\subsection{Illegal planting of GM crops in Hainan Province}

In March 2014, a number of companies and research institutions were exposed online to illegally conduct genetically modified crop experiments in Hainan. The Department of Agriculture of Hainan Province subsequently claimed that at the end of 2013, enforcement of law on illegal experiments on genetically modified crops was carried out and illegal crops were destroyed, and no contamination arising from the GMOs was detected. However, the Department of Agriculture of Hainan did not publish the names of the organizations engaging in GM crop experiments, nor did it provide any detail of the law enforcement. In April 2014, Beijing Evening News and some media provided news reports on this case, but no official response was received [18].

\subsection{The case of golden rice in a primary school at Hengnan County in Hunan Province}

Golden rice was a genetically modified rice developed by Syngenta in Switzerland. Technicians used transgenic technology to transfer carotene-converting enzyme into rice endosperm to increase the vitamin A content of rice. As carotene could make the rice golden yellow, the rice was thus called golden rice. On August 1, 2012, the American Journal of Clinical Medicine published a study titled " $\beta$-carotene in golden rice is as good as $\beta$-carotene in oil at providing vitamin A to children", claiming that the experiment study was conducted in an elementary school of Jiangkou Town at Hengnan County of Hunan Province in 2008. Dozens of elementary school students aged between 6 and 8 were required to eat this kind of rice. In doing so, researchers could well observe the effects of supplementation of vitamin A [19]. The publication of this research report received widespread attention. Having been investigated by the Center for Disease Control (CDC) of China, Zhejiang Academy of Medical Sciences as well as the CDC of Hunan province, this experiment study was found to have violated the relevant rules. However, no crime was involved. Members of the research team were disciplined for wrongdoing [20]. In September 2013, Tufts University made its apologies for the mishap.

\subsection{China's refusal to accept American GM corn}

In May 2014, the General Administration of Quality Supervision, Inspection and Quarantine of China published data, claiming that more than 1 million tons of American corn had been returned due to the detection of MIR162, a type of genetically modified ingredient not approved by the Ministry of Agriculture [21]. Although this act complied with the relevant rules and regulations of China, this act was interpreted as a political consideration. Terry Reilly, a senior commodity analyst at Futures International, argued that "if China is still importing (American corn), we have to feel that they are more like playing a political game" [22].

\section{Food safety guarantee system}

Having reviewed relevant cases of GM food safety guarantee system, we argue that the following issues deserve further discussion.

\subsection{The development of the safety system of GM soybeans}

At present, the rules and regulations concerning the safety and risk of GM soybeans and foods exist in The Food Safety Act [23], The Import and Export Trade Act [24] as well as Regulations on the Management of Genetically Modified Organisms and some others. However, these rules and regulations failed to achieve a perfect coordination and cooperation between different law enforcement agencies. Specifically, coordination should be improved between the office of food safety and risk monitoring, the office of quality supervision and risk detection as well as the office of public health and the administrative offices of agriculture, etc. 
It should be noted that The Measures for the Administration of the Inspection and Quarantine of the Genetically Modified Products Entering [25] and Exiting the Territory and The Labeling of Agricultural Genetically Modified Organisms of the No. 869 Announcement of the Ministry of Agriculture-1-2007 [26] are normative guidelines at best.

\subsection{The effectiveness of risk management of GM soybeans and foods}

In the field of safety management, China imports GM soybeans for forage and cooking oil. As a result, China requires the export countries to submit the data and methods used for GM products. However, the production tests of plant seeds may well be dispensed with according to Regulations on the Safety and Risks of Management of Genetically Modified Organisms. Currently, the bulk of imported GM soybeans are from the US and Brazil. It can be argued that making decisions by relying solely on the data submitted by export countries without initiating any well-designed studies by import country might be riddled with political and technological risks.

In terms of product labeling, although The Food Safety Act of China explicitly includes the requirement of labeling GM foods, it is not effectively implemented. Taking the most widely used blended cooking oil in China's market as an example, we find that many brands of the blended cooking oil relied on GM soybeans as raw materials. According to a study conducted by China Business Journal in 2018, many brands of blended oil used GM soybeans as raw materials and the fonts of label were small. In some cases, some brands claimed to be non-GM oil but actually used GM soybeans as raw materials. In June 2018, Fujian Wanglongshun Oil \& Foodstuff Co., Ltd. was fined RMB 1 million by the Market Supervision Office of Tingping Township at Minhou County, Fuzhou of Fujian Province for labeling genetically modified soybean oil as nontransgenic products. Consequently, 3,086 bottles of blended oil were confiscated [27].

\subsection{The system of risk detection and evaluation of GM soybeans and foods}

Although The Food Safety Act and The National Food Safety and Risk Monitoring and Management System [Effective] [28] and some others have made the detection of risks related to GM soybeans the top priority - the public spotlight, these rules and regulations fail to single the GM foods out for special treatment. Quite different than conventional food risks, the risks arising from GM foods are widely believed to be long-term and latent. Consequently, it is very hard for the conventional risk management system to produce any monitoring effect.

\subsection{The interconnectedness between the risk management of GM soybeans and foods and international treaties}

The Agreement on the Implementation of Sanitary and Phytosanitary Measures within the framework of WTO aimed to strike a balance between protecting the human, animal and plant health and promoting the healthy development of international trade in agricultural products. The purpose of this agreement was to protect the health of the people of each member state and in the meantime, prevent its member states from creating new trade barriers. To comply with the requirements of the agreement, the European Union formed the European Food Safety Authority (EFSA), carrying out independent food risks evaluation for member countries of the EU. The US, however, delegated its trade representatives to communicate regularly with WTO and its member states over the GM-related issues. But in China, no such a special agency exists. The only mechanism for dealing with GMOrelated issues is the inter-ministerial joint conference system created by the Ministry of Agriculture and Rural Affairs. Since the system of joint conference did not create a government entity and the primary function of which was to coordinate policy on food safety between ministries of this country, the effectiveness of the system paled in comparison with that of European countries and America. Certainly, it could not facilitate effective coordination between the safety management of GM soybeans and foods of China and international treaties. Without a doubt, it was not conducive to the prevention of international trade disputes.

\section{Discussion and conclusion}

In view of the problems in current regulatory system of GM soybean imports and the root causes for these problems, the governments may improve the following aspects.

\subsection{Greater legal power should be vested in higher tier of government agencies and coordination between different tiers of agencies should be strengthened}

The legal system concerned should be streamlined and the power of law enforcement should be vested in higher tier of government agencies. By making The Biosafety Act as a benchmark, the legislative body should further streamline The Regulations on the Safety Management of Genetically Modified Organisms and make parts of them become the law. In the meantime, The Measures for the Administration of the Inspection and Quarantine of the Genetically Modified Products Entering and Exiting the Territory and The National Food Safety and Risk Monitoring and Management System [Effective] should be re-issued as rules and stipulations of government agencies. We should further establish the national mandatory standards based on The Labeling of Agricultural Genetically Modified Organisms of the No. 869 Announcement of the Ministry of Agriculture-1-200\%. Meanwhile, we should strengthen the coordination between different agencies and systems and make the inspection and quarantine of GM product imports, product labeling and risk detection and assessment an organic unity. 


\subsection{The supervision should be intensified and the standard of supervision should continue to be refined}

First of all, supervision of imported GM soybeans for forage and cooking oil should be strengthened. Even if production tests of plant seeds may well be dispensed with, the safety certificates granted by export countries as supportive evidence should be provided as well. Secondly, the standard of labeling GM foods based on GM crops should further be refined and the supervision of the implementation should be strengthened. The crackdown on nonlabeling and false labeling should be intensified. It is expected that the GM products consumers' "right-to-know" should be protected.

\subsection{Developing a system aimed at detecting and evaluating risks related to GM products}

On the basis of existing system of food risk detection and evaluation, a special mechanism for detecting and evaluating the risks related to GM products should be developed. Under such a mechanism, special attention should be given to long-term and latent risk detection and evaluation. Meanwhile, it is advisable to invite the third party or social organizations to do the detection and evaluation in order to minimize the use of administrative resources. In this endeavor, the public are expected to achieve a deeper understanding of GM technology and GM products. The public are not to be alarmed when they are exposed to the information related to GM technology.

\subsection{International cooperation should be strengthened and trade conflicts should be avoided under the principle of improving food safety}

As a matter of fact, the supervision of the safety of imported GM soybeans is not purely an internal affair, it also involves the trade issue between nations. As a result, how to exercise effective food safety control within the existing framework of international trade is still an important issue that needs to be seriously considered. However, the agenda set by current inter-ministerial joint conference system for the management of agricultural GM organisms does not incorporate the international trade issue concerning GM foods. Given the circumstances, it is imperative that the status of the Ministry of Commerce be elevated in the mechanism of the joint conference system. In doing so, it may facilitate the solution of trade disputes arising from food safety control measures.

\section{References}

1. Xinhua News Agency, The planting area of GM crops continues to increase, Retrieved from http://www.81.cn/ gjzx/2019-09/02/content-9608468.htm (published on Sep 1, 2019; accessed on Aug 8, 2020.) (in Chinese)
2. China news Agency, Ministry of agriculture and rural areas: China's soybean import is expected to exceed 100 million tons in 2020, Retrieved from https://www.chinanews.com $/ \mathrm{cj} /$ 2020/12-24/9370281.shtml (published on Dec 24, 2020; accessed on Apr 20, 2021.) (in Chinese)

3. J.E. Losey, L.S. Rayor, M.E. Carter, Transgenic pollen harms monarch larvae, Nature 399, 214 (1999)

4. Cartagena Protocol on Biosafety 2000. Retrieved from https://bch.cbd.int/protocol/ (enters into force on Sep 11, 2003)

5. D.J. Schnier, Genetically Modified Organisms and the Cartagena Protocol. Fordham Environ, Law Review 12, 377-415 (2000)

6. M. Lamping, Shackles for Bees? The ECJ's Judgment on GMO-Contaminated Honey, Eur. J. Risk Regul. 3, 123-129 (2012)

7. L. Jonathan, GE Soybeans Give Altered Milk and Stunted Offspring, Researchers Find. Independent Science News. Retrieved from https://www.independentsciencenews.org/ news/ge-soybeans-give-altered-milk-and-stunted-offspringresearchers-find/ (2015)

8. R. Tudisco, M. Mastellone, M. I. Cutrignelli, P. Lombardi, F. Bovera, N. Mirabella, G. Piccolo, S. Cababro, L. Avallone, F. Infascelli, Fate of transgenic DNA and evaluation of metabolic effects in goats fed genetically modified soybean and in their offsprings, Animal 4, 1662-1671 (2010)

9. G.H. Xu, H.Y. Wang, J. Liu, Effects of RRS on the amount and diversity of bacteria in rhizospheric soil, J. Biol. 29, 4535-4541 (2009)

10. Z.H. Liu, G.H. Xu, H.Y. Wang, J. Liu, Effects of Roundup Ready Soybean (RRS) on Microorganisms and Nitrogen Transformation in the Rhizospheric Soil, J. Agro-Environ. Sci. 29, 1341-1345 (2010)

11. F.S. Cui, A panorama of genetic contamination, Environ. Guide 45-46 (2001)

12. Y.F. Zhang, Study on environmental persistence of exogenous genes of BT rice and expressed proteins. Zhejiang University. (Unpublished Doctoral Dissertation)

13. Science \& Technology Daily, People Republic of China (PRC), The genes commonly seen in GM crops are detected in human bodies? Rumor!, Retrieved from http://news. southcn.com/shouyeyaowen/content/2016-04/13/content 145893405_2.htm (published on Sep 1, 2019; accessed on Aug 29, 2020) (in Chinese)

14. Science \& Technology Daily, People Republic of China (PRC), Striving to cultivate the GM crops that can generate insulin, Science \& Technology Daily, Retrieved from http:// news.southcn.com/shouyeyaowen/content/2016-04/13/con tent_145893405_2.htm (published on Apr 4, 2016; accessed on Aug 29, 2020) (in Chinese)

15. China's State Council, Regulations on Administration of Agricultural Genetically Modified Organisms Safety, Available online: http://www.gov.cn/gongbao/content/2019/con tent_5468924.htm (accessed on Apr 20, 2021) (in Chinese)

16. Ministry of agriculture, People Republic of China (PRC), Administrative Measures for Labeling Agricultural GMO Marks, Available online: http://www.moa.gov.cn/ztzl/ zjyqwgz/zcfg/201007/t20100717_1601302.htm (accessed on Apr 20, 2021) (in Chinese)

17. Civil Judgment of the Intermediate Court of Huai' an, Jiangsu Province (2015) No. 02573 
18. W.Y. Su, Who planted illegal GM crops in Hainan?. Beijing Evening News, April 2, 2014

19. G.W. Tang, Y.M. Hu, S.A. Yin, Y. Wang, G.E. Dallal, M.A. Grusak, R.M. Russell, $\beta$-Carotene in Golden Rice is as good as $\beta$-carotene in oil at providing vitamin A to children, Am. J. Clin. Nutr. 3, 658-664 (2012)

20. The Center for Disease Control (CDC) of China, Zhejiang Academy of Medical Sciences, the CDC of Hunan province. Announcement of the investigation result of the study on " $\beta$-carotene in golden rice is as good as $\beta$-carotene in oil at providing vitamin A to children", Retrieved from http:/ www. chinacdc.cn/zxdt/201212/t20121206_72794.html (published on Dec 6, 2012; accessed on Aug 20, 2020.) (in Chinese)

21. Xinhua News Agency, China's refusal to import America GM corn captured world's attention, Retrieved from http:// news.southcn.com/shouyeyaowen/content/2016-04/13/con tent_145893405_2.htm (published on Apr 13, 2016; accessed on Aug 20, 2020.) (in Chinese)

22. Hexun Net, China refused to import American GM corn, trade dispute continued, Retrieved from http://news.bioon. com/article/6639806.html (published on Dec 16, 2013; accessed on Aug 25, 2020.) (in Chinese)

23. Chinese People's Congress, Food Safety Law of the People's Republic of China, Available online: http://www.npc .gov.cn/npc/c30834/201901/c6d064de8295489288ec1383 b33212ee.shtml (accessed on Apr 20, 2021) (in Chinese)
24. Chinese People's Congress, Foreign Trade Law of the People's Republic of China, Available online: http://www. npc.gov.cn/wxzl/gongbao/2017-02/21/content_2007588.htm (accessed on Apr 20, 2021) (in Chinese)

25. State General Administration of the People's Republic of China for Quality Supervision and Inspection and Quarantine, Measures for the Administration on the Inspection and Quarantine of the Genetically Modified Products Entering and Exiting the Territory, Available online: http://www.gov.cn/gongbao/content/2005/content_ 63203.htm (accessed on Apr 20, 2021) (in Chinese)

26. Ministry of agriculture, People Republic of China (PRC), Announcement No. 869 of the Ministry of Agriculture and Rural Affairs, Available online: http://www.moa .gov.cn/nybgb/2007/dqq/201806/t20180614_6151996.htm (accessed on Apr 20, 2021) (in Chinese)

27. The Beijing News, GM soybean oil were found to be posing as non-GM blended oil, Wanglongshun Oil \& Foodstuff Co., Ltd of Fujian Province was fined more than 1 million yuan, 21 June 2018

28. National Medical Products Administration, People Republic of China (PRC), Notice on Issuing "Food Safety Risk Monitoring and Management Regulations (Trial)", Available online: http://www.nhc.gov.cn/sps/s5853/201002/ df6c5689c712424fadfbbe87045663c5.shtml (accessed on Apr 20, 2021) (in Chinese)

Cite this article as: YinTong Yu, The study of the impact of genetically modified soybean imports on China's food safety management, Int. J. Metrol. Qual. Eng. 12, 18 (2021) 